\title{
Effect of Chitosan and Alginate Concentration on Size and Bactericidal Activity against Escherichia coli of Chitosan/Alginate/Silver Nanoparticle Beads
}

\author{
Pawika Mahasawat ${ }^{1, a^{*}}$, Ketsarin Hlongkeaw ${ }^{1, b}$ \\ and Sutthida Charoenrit ${ }^{1, \mathrm{C}}$ \\ ${ }^{1}$ Programme in Biology and Applied Biology, Faculty of Science and Technology, \\ Songkhla Rajabhat University, Songkhla, Thailand, 90000 \\ apawika_mahasawat@hotmail.com, bketsarin_miko@hotmail.com, \\ crocheedacharoenrit999@gmail.com
}

Keywords: silver nanoparticles, chitosan/alginate/silver nanoparticle beads, Escherichia coli

\begin{abstract}
Silver nanoparticles have been used in combination with biological polymer for antibacterial application. This study prepared chitosan/alginate/AgNP beads with varying chitosan and alginate concentration to use as an antibacterial material. The sizes of neat beads were larger $(1286 \pm 172,1344 \pm 142$ and $1529 \pm 73 \mu \mathrm{m}$ for $\mathrm{C} 1, \mathrm{C} 2$ and $\mathrm{C} 3$, respectively) with increasing concentration of chitosan and alginate. Moreover, smaller beads were observed for the chitosan/alginate/AgNP beads, in which their sizes were $1151 \pm 201,1261 \pm 204$ and $1324 \pm$ $198 \mu \mathrm{m}$ for S1, S2 and S3, respectively, when compared to the chitosan/alginate beads. Furthermore, the minimum bactericidal concentration (MBC) of chitosan/alginate/AgNP beads against $E$. coli was 10,10 and $3 \mu \mathrm{g} / \mathrm{ml}$ for S1, S2 and S3, respectively. This study suggested that the beads with the higher concentration of chitosan and alginate resulted in the greater bactericidal activity. Therefore, the chitosan/alginate/AgNP beads prepared in this study showed the bactericidal activity which can be used for antibacterial application.
\end{abstract}

\section{Introduction}

The use of silver nanoparticles (AgNPs) has been vastly increasing due to the claim of lower toxicity when compared to silver compounds, and a broad antibacterial activity of silver still retains even a form of nanoparticles [1,2,3]. Therefore, AgNPs have been recently used for many applications, such as consumer products [4] and medical application [5]. AgNPs in combination with biological polymer have also been reported $[6,7,8,9]$. For examples, $N, N, N$-trimethyl chitosan/alginate beads loaded with AgNPs were successfully prepared [6]. The diameters of dry neat beads (with no AgNPs) and dry beads with AgNPs were about 0.1-0.2 mm [6]. Moreover, the bactericidal activity of the neat beads against $E$. coli in PBS, $\mathrm{pH} 7.4$ was lower than that of the beads loaded with AgNPs $(3.3 \mathrm{mg} / \mathrm{ml})$ which showed about $91 \%$ inhibition of the viability of $E$. coli [6]. This previous study suggested that the antibacterial activity of the beads loaded with AgNPs of $3.3 \mathrm{mg} / \mathrm{ml} \mathrm{might} \mathrm{be} \mathrm{from} \mathrm{the} \mathrm{silver} \mathrm{ion}\left(\mathrm{Ag}^{+}\right)$released into the system [6]. Furthermore, another study reported that no $\mathrm{Ag}^{+}$was released from $N, N, N$-trimethyl chitosan/alginate/AgNP beads in buffer, $\mathrm{pH} 2$ but this release could be observed in buffer, $\mathrm{pH} 7.4$ [9]. This might be because of electric repulsions between hydronium ion $\left(\mathrm{H}_{3} \mathrm{O}^{+}\right)$and the positive charge of chitosan/alginate beads, which could inhibit the swelling of the beads and the release of $\mathrm{Ag}^{+}$in buffer, $\mathrm{pH} 2$ [9]. Moreover, the carboxylic group $(-\mathrm{COOH})$ of alginate are not ionized at $\mathrm{pH} 2$, which will also decrease the release of $\mathrm{Ag}^{+}$from the beads [9]. On the other hand, at $\mathrm{pH} 7.4$, the carboxylic group of alginate will be ionized as follows (Eq.1):

$$
-\mathrm{COOH}+\mathrm{H}_{2} \mathrm{O} \rightarrow-\mathrm{COO}-+\mathrm{H}_{3} \mathrm{O}^{+}
$$

This can promote the interaction between carboxylate group of alginate and water molecules, resulted in the swelling of the beads and eventually the release of $\mathrm{Ag}^{+}$[9]. 
However, to our knowledge, the effect of concentration of chitosan and alginate on sizes and bactericidal activity of chitosan/alginate beads loaded with AgNPs has not yet studied. Therefore, in this present study, chitosan/alginate/AgNP beads with varying chitosan and alginate concentrations were prepared. Subsequently, the sizes of these beads were investigated using an optical microscope, and the bactericidal activity of these beads against E. coli was determined in PBS, pH 7.4.

\section{Materials and Methods}

All chemicals were purchased from Sigma-Aldrich (Singapore), unless otherwise indicated.

Preparation of chitosan/alginate/AgNP beads. There are two steps used to prepare chitosan/alginate/AgNP beads as follows:

Preparation of AgNP suspension. AgNPs were prepared according to Jana et al. [10] as follows: The mixture $(600 \mathrm{ml})$ of silver nitrate $(0.25 \mathrm{mM})$ and sodium citrate $(0.25 \mathrm{mM})$ was prepared at room temperature. Sodium borohydride $(10 \mathrm{mM}, 18 \mathrm{ml})$ was added to such mixture under magnetic stirring at room temperature, and this mixture was vigorously stirred for a further $2 \mathrm{~h}$. The AgNP suspension ( $\sim 600 \mathrm{ml}$ ) was then evaporated (Heidolph, Germany) at $37^{\circ} \mathrm{C}$ until a final volume of $50 \mathrm{ml}$ was obtained.

Preparation of chitosan/alginate/AgNP beads. The concentration and volume of chitosan, alginate, calcium nitrate and AgNPs were shown in Table 1.

Table 1 Concentration and volume of chitosan, alginate, calcium nitrate and AgNPs used to prepared chitosan/alginate/AgNP beads

\begin{tabular}{ccccc}
\hline Sample & $\begin{array}{c}\text { Chitosan solution } \\
{[25 \mathrm{ml}], \% \mathrm{w} / \mathrm{v}}\end{array}$ & $\begin{array}{c}\text { Alginate solution } \\
{[12.5 \mathrm{ml}], \% \mathrm{w} / \mathrm{v}}\end{array}$ & $\begin{array}{c}\text { AgNP suspension } \\
{[12.5 \mathrm{ml}]}\end{array}$ & $\begin{array}{c}\text { Calcium nitrate solution } \\
{[300 \mathrm{ml}], \% \mathrm{w} / \mathrm{v}}\end{array}$ \\
\hline S1 & 0.05 & 2 & - & 1 \\
S2 & 0.1 & 4 & - & 2 \\
S3 & 0.15 & 6 & - & 3 \\
\hline
\end{tabular}

AgNP suspension (section 1.1) and chitosan solution was firstly mixed (Table 1) under magnetic stirring at room temperature for $30 \mathrm{~min}$. This mixture was subsequently mixed with alginate solution (Table 1) under magnetic stirring at room temperature for a further $30 \mathrm{~min}$. Then, this mixture was dropped into calcium nitrate solution (Table 1) using a syringe. The chitosan/alginate/AgNP beads were formed. These beads were dried at room temperature for $24 \mathrm{~h}$, which followed by at $80^{\circ} \mathrm{C}$ for $2 \mathrm{~h}$. These beads were kept in a desiccator until they were used.

Neat chitosan/alginate beads (with no AgNPs; a control) were prepared and dried using the same procedure as being used with chitosan/alginate/AgNP beads. The concentration and volume of chitosan, alginate and calcium nitrate were presented in Table 2.

Table 2 Concentration and volume of chitosan, alginate and calcium nitrate used to prepared neat chitosan/alginate beads

\begin{tabular}{cccc}
\hline Sample & $\begin{array}{c}\text { Chitosan solution } \\
{[25 \mathrm{ml}], \% \mathrm{w} / \mathrm{v}}\end{array}$ & $\begin{array}{c}\text { Alginate solution } \\
{[25 \mathrm{ml}], \% \mathrm{w} / \mathrm{v}}\end{array}$ & $\begin{array}{c}\text { Calcium nitrate solution } \\
{[300 \mathrm{ml}], \% \mathrm{w} / \mathrm{v}}\end{array}$ \\
\hline $\mathrm{C} 1$ & 0.05 & 1 & 1 \\
$\mathrm{C} 2$ & 0.1 & 2 & 2 \\
$\mathrm{C} 3$ & 0.15 & 3 & 3 \\
\hline
\end{tabular}

Size measurement. Size of the beads was measured using an optical microscope. A diameter of the beads was measured from four different positions of the diameter of the beads, and at least 13 beads were calculated (mean \pm S.D.). 
Antibacterial activity of chitosan/alginate/AgNP beads against $E$. coli. The minimum bactericidal concentration (MBC) of chitosan/alginate/AgNP beads was investigated against $E$. coli according to the procedure of Li et al. and Martins et al. $[6,11,12]$ as follows:

E. coli was cultured in nutrient broth (NB) at room temperature overnight. Then, they were diluted with PBS, pH 7.4 to obtain $E$. coli concentration of $10^{5}$ cells $/ \mathrm{ml}$ by measuring the optical density (OD) at $600 \mathrm{~nm}\left(\mathrm{OD}_{600}\right.$ of 0.1 is equal to $10^{8}$ cells $\left./ \mathrm{ml}\right)$. Then, E. coli suspension in PBS $\left(10^{5}\right.$ cells $\left./ \mathrm{ml} ; 3 \mathrm{ml}\right)$ was added to each well of a 6 -well plate which contained different concentrations of chitosan/alginate/AgNP beads (1, 3, 5, 7 and $10 \mu \mathrm{g} / \mathrm{ml}$ of AgNPs). The plate was incubated at $37^{\circ} \mathrm{C}$ for $24 \mathrm{~h}$. The viable $E$. coli was counted as follows: E. coli was diluted with PBS, $\mathrm{pH}$ 7.4. $0.1 \mathrm{ml}$ of each dilution was spread on nutrient agar (NA). This NA was incubated at $37^{\circ} \mathrm{C}$ for $24 \mathrm{~h}$. The number of visible colony was counted and reported as colony forming unit per milliliter (CFU/ml).

\section{Results and Discussion}

The use of AgNPs in combination with biological polymer has been previously reported $[6,7,8,9]$. This study prepared chitosan/alginate/AgNP beads for antibacterial application. However, the concentration of chitosan and alginate might affect sizes and an antibacterial activity of these beads. Therefore, this study reported the effect of the concentration of biological polymers, chitosan and alginate, on the size and antibacterial activity of chitosan/alginate/AgNP beads. Moreover, these beads were kept in the dry state, which have been claimed to show more advantages than using those in wet state, such as they are easy to handle and store as well as greater precision during weighing [13].

Morphology and size of chitosan/alginate/AgNP beads. The morphology and size of chitosan/alginate beads and chitosan/alginate/AgNP beads are presented in Fig. 1. For chitosan/alginate beads, C1 (Fig. 1A) exhibited irregular shape, while C2 (Fig. 1B) and C3 (Fig. 1C) showed nearly spherical shape. The surface of $\mathrm{C} 1$ and $\mathrm{C} 2$ seemed to be rough, whereas $\mathrm{C} 3$ had a smooth surface. This might be suggested that the higher concentration of both chitosan and alginate resulted in the smoother surface of the beads. All chitosan/alginate/AgNP beads, S1 (Fig. 1D), S2 (Fig. 1E) and S3 (Fig. 1F), exhibited irregular shape, and their surfaces were rough. Moreover, the color of the chitosan/alginate/AgNP beads was different from the beads with no AgNPs. Previous study has shown that the neat chitosan/alginate beads (with no AgNPs) had white coloration whereas the beads with AgNPs were yellowish [6]. Therefore, the color change of the beads prepared in this present study could then confirm the existence of AgNPs inside the beads.

The sizes of chitosan/alginate beads were $1286 \pm 172,1344 \pm 142$ and $1529 \pm 73 \mu \mathrm{m}$ for C1, C2 and C3, respectively. Smaller beads were observed for chitosan/alginate/AgNP beads, in which their sizes were $1151 \pm 201,1261 \pm 204$ and $1324 \pm 198 \mu \mathrm{m}$ for S1, S2 and S3, respectively. Similar results were previously reported [14]. They showed that larger beads were observed in the neat alginate beads $(485 \pm 16 \mu \mathrm{m})$, which was followed by the alginate beads with $4 \%$ AgNPs $(440 \pm 23 \mu \mathrm{m})$ and the alginate beads with $8 \%$ AgNPs $(411 \pm 15 \mu \mathrm{m})$, respectively, when determining with an optical microscope [14]. This might be because of the presence of the charged AgNPs inside the beads which can cause a higher electrical force and then result in smaller beads $[14,15]$. 
A

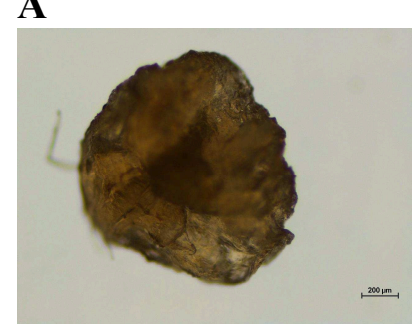

D

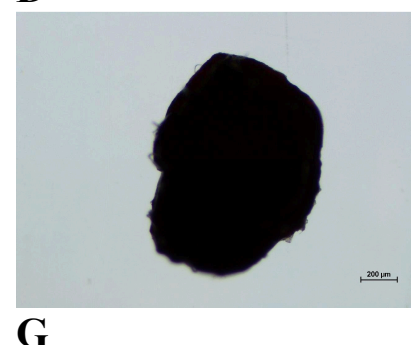

B

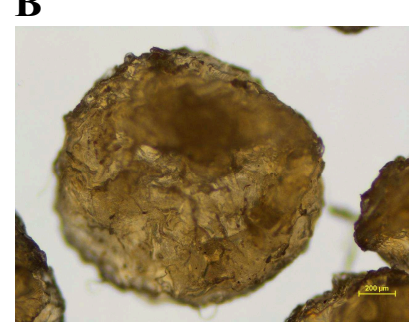

$\mathbf{E}$

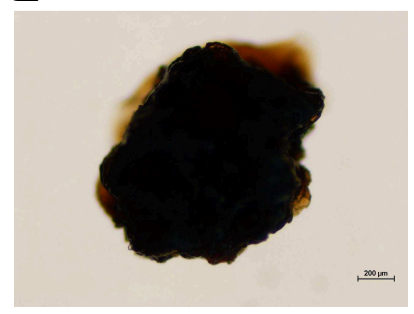

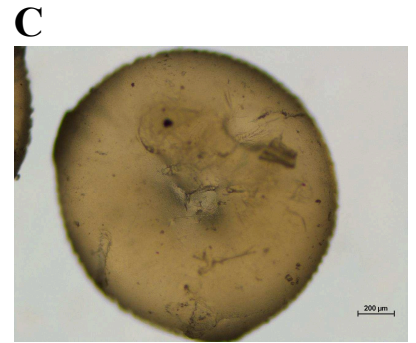

$\mathbf{F}$
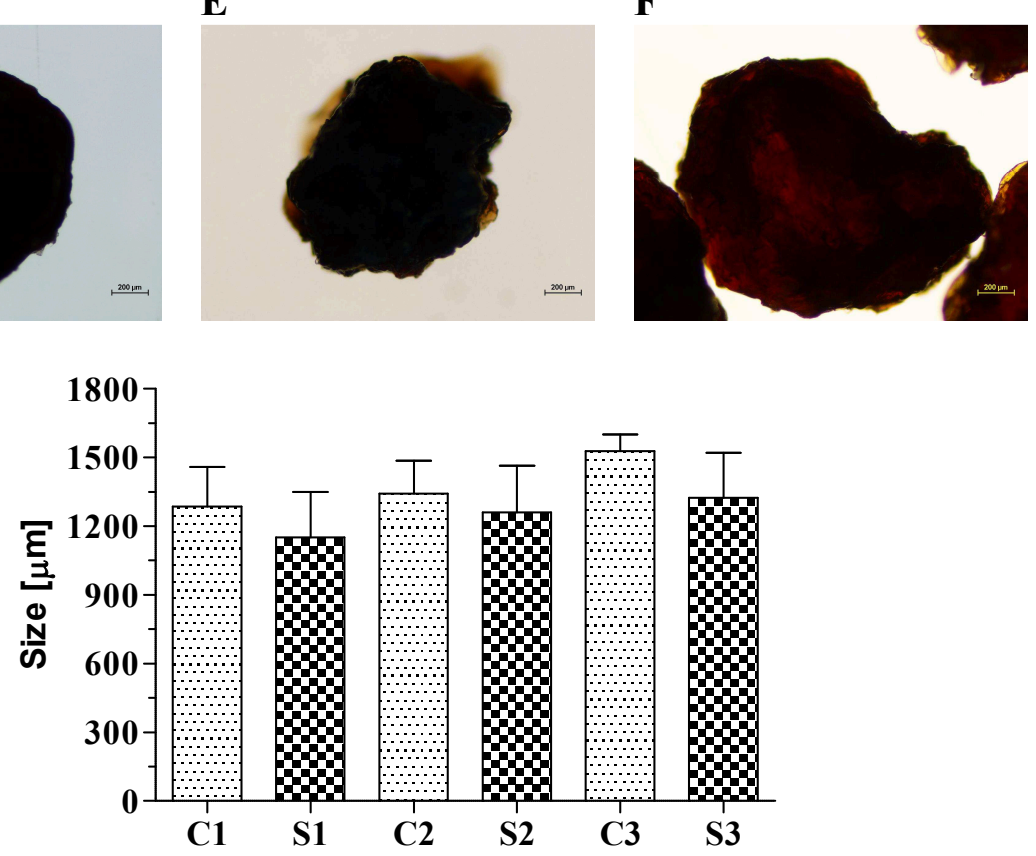

Fig. 1 Morphology and size of chitosan/alginate beads and chitosan/alginate/AgNP beads

Morphology and size of chitosan/alginate beads were presented as follows: (A) C1; (B) C2; and (C) $\mathrm{C} 3$, whereas the morphology and size of chitosan/alginate/AgNP beads were demonstrated as follows: (D) S1; (E) S2; and (F) S3. The mean diameters of all beads are presented in (G). No significant difference was observed between each bead at $p<0.05$ using an independent-samples $\mathrm{T}$ test.

Antibacterial activity of chitosan/alginate/AgNP beads against $E$. coli. An antibacterial activity of chitosan/alginate beads $(\mathrm{C} 1, \mathrm{C} 2$ and $\mathrm{C} 3)$ and chitosan/alginate/AgNP beads (S1, S2 and $\mathrm{S} 3$ ) is presented in Fig.2. The viability of E. coli after exposure to chitosan/alginate beads was higher than that after treatment with chitosan/alginate/AgNP beads. This result suggested that the beads with AgNPs showed lower viability of E. coli than that observed with the beads with no AgNPs. Similar results were observed in the previous literature [6]. The chitosan/alginate beads loaded with AgNPs $(3.3 \mathrm{mg} / \mathrm{ml})$ resulted in $91 \%$ inhibition of the viability of E. coli in PBS, pH 7.4, while the chitosan/alginate beads with no AgNPs showed no bactericidal activity [6]. Moreover, this present study showed that the bactericidal activity of chitosan/alginate beads (with no AgNPs) was greater when higher concentration of chitosan and alginate was employed. Previous study has reported the antibacterial activity of chitosan [16], therefore, this greater bactericidal activity observed in chitosan/alginate beads might obviously be from higher concentration of chitosan blended in the beads.

Furthermore, the minimum bactericidal concentration (MBC) of chitosan/alginate/AgNP beads was 10,10 and $3 \mu \mathrm{g} / \mathrm{ml}$ for S1, S2 and S3, respectively (Fig.2). The MBC of S3 was the lowest, when compared with $\mathrm{S} 1$ and S2. This is corresponded to the higher concentration of chitosan blended in S3, when compared with S1 and S2. To our knowledge, this is the first study to show that the higher concentration of chitosan and alginate blended in the beads containing AgNPs resulted in the greater bactericidal activity against $E$. coli. 


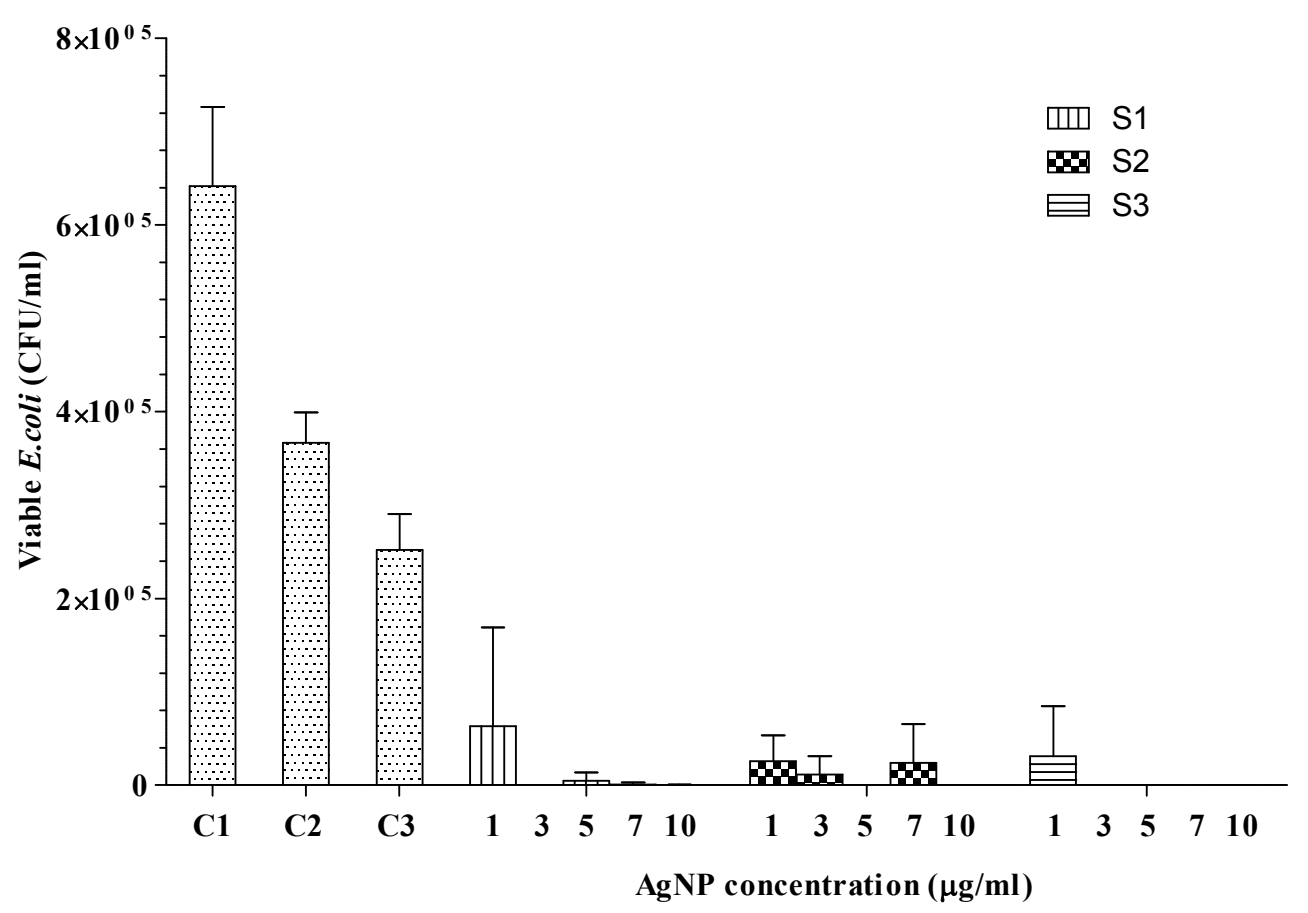

Fig. 2 Antibacterial activity of chitosan/alginate beads and chitosan/alginate/AgNP beads against E. coli

Antibacterial activity of chitosan/alginate beads (C1, C2 and $\mathrm{C} 3)$ and chitosan/alginate/AgNP beads (S1, S2 and S3) was investigated in PBS, pH 7.4 against E. coli. After $24 \mathrm{~h}$ incubation at $37^{\circ} \mathrm{C}$, the viable $E$. coli was counted and reported as colony forming unit per milliliter $(\mathrm{CFU} / \mathrm{ml})$.

\section{Summary}

In summary, chitosan/alginate/AgNP beads used as an antibacterial material were successfully prepared in this study. When the higher concentration of chitosan and alginate was used to prepare the beads, the sizes of both neat beads and beads loaded with AgNPs were larger. However, smaller beads were observed for the chitosan/alginate/AgNP beads, when compared to the neat beads. Furthermore, the bactericidal activity of chitosan/alginate/AgNP beads against E. coli was greater with increasing concentration of chitosan and alginate. Therefore, the bactericidal beads prepared in this study can be used for antibacterial application.

\section{Acknowledgement}

The authors would like to thank Institute of Research and Development, Songkhla Rajabhat University for providing the funding.

\section{References}

[1] R. Foldbjerg, P. Olesen, M. Hougaard, D.A. Dang, H.J. Hoffmann and H. Autrup, PVP-coated silver nanoparticles and silver ions induce reactive oxygen species, apoptosis and necrosis in THP-1 monocytes. Toxicol Lett. 190 (2009) 156-162.

[2] A. Ivask, I. Kurvet, K. Kasemets, I. Blinova, V. Aruoja, S. Suppi, H. Vija, A. Kakinen, T. Titma, M. Heinlaan, M. Visnapuu, D. Koller, V. Kisand and A. Kahru, Size-dependent toxicity of silver nanoparticles to bacteria, yeast, algae, crustaceans and mammalian cells in vitro. PLOS One. 9 (2014) 1-14.

[3] F. Martinez-Gutierrez, P.L. Olive, A. Banuelos, E. Orrantia, N. Nino, E.M. Sanchez, F. Ruiz, H. Bach and Y. Av-Gay, Synthesis, characterisation, and evaluation of antimicrobial and cytotoxic effect of silver and titanium nanoparticles. Nanomedicine. 6 (2010) 681-688. 
[4] H.Y. Lee, H.K. Park, Y.M. Lee, K. Kim and S.B. Park, A practical procedure for producing silver nanocoated fabric and its antibacterial evaluation for biomedical applications. Chem Commun. 28 (2007) 2959-2961.

[5] K. Chaloupka, Y. Malam and A.M. Seifalian, Nanosilver as a new generation of nanoproduct in biomedical applications. Trends Biotechnol. 28 (2010) 580-588.

[6] A.F. Martins, J.P. Monteiro, E.G. Bonafe, A.P. Gerola, C.T.P. Silva, E.M. Girotto, A.F. Rubira and E.C. Muniz, Bactericidal activity of hydrogel beads based on $N, N, N$-trimethyl chitosan/alginate complexes loaded with silver nanoparticles. Chin Chem Lett. 26 (2015) 1129-1132.

[7] A. Travan, C. Pelillo, I. Donati, E. Marsich, M. Benincasa, T. Scarpa, S. Semeraro, G. Turco, R. Gennaro and S. Paoletti, Non-cytotoxic silver nnaoparticles-polysaccharide nanocomposites with antimicrobial activity. Biomacromolecules. 10 (2009) 1429-1435.

[8] J. Stojkovska, D. Kostic, Z. Jovanovic, M. Vukasinovic-Sekulic, V. Miskovic-Stankovic and B. Obradovic, A comprehensive approach to in vitro functional evaluation of $\mathrm{Ag} /$ alginate nanocomposite hydrogels. Carbohydr Polym. 111 (2014) 305-314.

[9] A.F. Martins, H.D.M. Follmann, J.P. Monteiro, E.G. Bonafe, S. Nocchi, C.T.P. Silva, C.V. Nakamura, E.M. Girotto, A.F. Rubira and E.C. Muniz, Polyelectrolyte complex containing silver nanoparticles with antitumor property on Caco-2 colon cancer cells. Int J Biol Macromol. 79 (2015) 748-755.

[10] N.R. Jana, L. Gearheart and C.J. Murphy, Wet chemical synthesis of silver nanorods and nanowires of controllable aspect ratio. Chem Commun. (2001) 617-618.

[11] W.R. Li, X.B. Xie, Q.S. Shi, H.Y. Zeng, Y.S. Ou-Yang and Y.B. Chen, Antibacterial activity and mechanism of silver nanoparticles on Escherichia coli, Appl Microbiol Biotechnol, 85 (2010) 1115-1122.

[12] W.R. Li, X.B. Xie, Q.S. Shi, S.S. Duan, Y.S. Ou-Yang, and Y.B. Chen, Antibacterial effect of silver nanoparticles on Staphylococcus aureus, Biometals, 24 (2011) 135-141.

[13] E. Torres, Y.N. Mata, M.L. Blazquez, J.A. Munoz, F. Gonzalez and A. Ballester, Gold and silver uptake and nanoprecipitation on calcium alginate beads. Langmuir. 21 (2005) 7951-7958.

[14] P. Pankongadisak, U.R. Ruktanonchai, P. Supaphol and O. Suwantong, Development of silver nanoparticles-loaded calcium alginate beads embedded in gelatin scaffolds for use as wound dressings. Polym Int. 64 (2015) 275-283.

[15] P. Shi, P. He, T.K.H. The, Y.S. Morsi and J.C.H. Goh, Parametric analysis of shape changes of alginate beads. Powder Technology. 210 (2011) 60-66.

[16] A. Landriscina, J. Rosen and A.J. Friedman, Biodegradable chitosan nanoparticles in drug delivery for infectious disease. Nanomedicine. 10 (2015) 1609-19. 